University of Wollongong

Research Online

Faculty of Engineering and Information

Faculty of Engineering and Information

Sciences - Papers: Part A

Sciences

$1-1-2015$

Carbothermal reduction of quartz in methane-hydrogen-argon gas mixture

Xiang Li

University of Wollongong, x|450@uowmail.edu.au

Guangqing Zhang

University of Wollongong, gzhang@uow.edu.au

Kai Tang

SINTEF, Trondheim, Norway

Oleg Ostrovski

University of New South Wales, o.ostrovski@unsw.edu.au

Ragnar Tronstad

Elkem AS

Follow this and additional works at: https://ro.uow.edu.au/eispapers

Part of the Engineering Commons, and the Science and Technology Studies Commons

Research Online is the open access institutional repository for the University of Wollongong. For further information contact the UOW Library: research-pubs@uow.edu.au 


\title{
Carbothermal reduction of quartz in methane-hydrogen-argon gas mixture
}

\begin{abstract}
Synthesis of silicon carbide ( $\mathrm{SiC}$ ) by carbothermal reduction of quartz in a $\mathrm{CH} 4-\mathrm{H} 2-\mathrm{Ar}$ gas mixture was investigated in a laboratory fixed-bed reactor in the temperature range of $1573 \mathrm{~K}$ to $1823 \mathrm{~K}\left(1300^{\circ} \mathrm{C}\right.$ to $1550^{\circ} \mathrm{C}$ ). The reduction process was monitored by an infrared gas analyser, and the reduction products were characterized by LECO, XRD, and SEM. A mixture of quartz-graphite powders with $\mathrm{C} / \mathrm{SiO} 2$ molar ratio of 2 was pressed into pellets and used for reduction experiments. The reduction was completed within 2 hours under the conditions of temperature at or above $1773 \mathrm{~K}\left(1500^{\circ} \mathrm{C}\right)$, methane content of 0.5 to 2 vol pct, and hydrogen content $\geq 70$ vol pct. Methane partially substituted carbon as a reductant in the SiC synthesis and enhanced the reduction kinetics significantly. An increase in the methane content above 2 vol pct caused excessive carbon deposition which had a detrimental effect on the reaction rate. Hydrogen content in the gas mixture above 70 vol pct effectively suppressed the cracking of methane.
\end{abstract}

\section{Keywords}

reduction, quartz, methane, carbothermal, hydrogen, mixture, argon, gas

Disciplines

Engineering | Science and Technology Studies

\section{Publication Details}

Li, X., Zhang, G., Tang, K., Ostrovski, O. \& Tronstad, R. (2015). Carbothermal reduction of quartz in methane-hydrogen-argon gas mixture. Metallurgical and Materials Transactions B: Process Metallurgy and Materials Processing Science, 46 (5), 2384-2393. 


\title{
Carbothermal Reduction of Quartz in Methane- Hydrogen-Argon Gas Mixture
}

\author{
XIANG LI, GUANGQING ZHANG, KAI TANG, OLEG OSTROVSKI, \\ and RAGNAR TRONSTAD
}

\begin{abstract}
Synthesis of silicon carbide ( $\mathrm{SiC}$ ) by carbothermal reduction of quartz in a $\mathrm{CH}_{4}-\mathrm{H}_{2}-\mathrm{Ar}$ gas mixture was investigated in a laboratory fixed-bed reactor in the temperature range of $1573 \mathrm{~K}$ to $1823 \mathrm{~K}\left(1300{ }^{\circ} \mathrm{C}\right.$ to $\left.1550{ }^{\circ} \mathrm{C}\right)$. The reduction process was monitored by an infrared gas analyser, and the reduction products were characterized by LECO, XRD, and SEM. A mixture of quartz-graphite powders with $\mathrm{C} / \mathrm{SiO}_{2}$ molar ratio of 2 was pressed into pellets and used for reduction experiments. The reduction was completed within 2 hours under the conditions of temperature at or above $1773 \mathrm{~K}\left(1500{ }^{\circ} \mathrm{C}\right)$, methane content of 0.5 to $2 \mathrm{vol} \mathrm{pct}$, and hydrogen content $\geq 70$ vol pct. Methane partially substituted carbon as a reductant in the SiC synthesis and enhanced the reduction kinetics significantly. An increase in the methane content above 2 vol pct caused excessive carbon deposition which had a detrimental effect on the reaction rate. Hydrogen content in the gas mixture above 70 vol pct effectively suppressed the cracking of methane.
\end{abstract}

DOI: $10.1007 / \mathrm{s} 11663-015-0407-\mathrm{x}$

(C) The Minerals, Metals \& Materials Society and ASM International 2015

\section{INTRODUCTION}

SILICON carbide $(\mathrm{SiC})$ has a long history as a cutting material, refractory material, high-temperature semiconductor, and in other advanced applications. ${ }^{[1]}$ $\mathrm{SiC}$ is distinguished by a combination of high thermal conductivity (higher than that of copper), hardness second to diamond, high thermal stability, and chemical inertness. It is also a wide-bandgap semiconductor material with high breakdown electric field strength and high saturated drift velocity of electrons. ${ }^{[2]}$

The overall reaction for the formation of $\mathrm{SiC}$ through carbothermal reduction of silica can be represented as

$$
\begin{aligned}
\mathrm{SiO}_{2}(\mathrm{~s})+3 \mathrm{C}(\mathrm{s}) & =\mathrm{SiC}(\mathrm{s})+2 \mathrm{CO}(\mathrm{g}) \\
\Delta \mathrm{G}^{\circ} & =598.18-0.3278 T(\mathrm{~kJ})
\end{aligned} .
$$

This reaction is strongly endothermic with $\Delta H_{298}^{\mathrm{deg}}=$ $618.5 \mathrm{~kJ} .{ }^{[3]}$ The basic building block of an $\mathrm{SiC}$ crystal is the tetrahedron of four carbon atoms with a silicon atom in the center. Synthesis of $\mathrm{SiC}$ materials requires high temperatures $\left[>1273 \mathrm{~K}\left(1000^{\circ} \mathrm{C}\right)\right] .^{[4,5]}$ The commercial production of $\mathrm{SiC}$ was established as early as

XIANG LI, Ph.D. Student, and GUANGQING ZHANG, Principal Supervisor, are with the School of Mechanical, Materials and Mechatronic Engineering, University of Wollongong, Wollongong, NSW 2522, Australia. Contact e-mail: x1450@uowmail.edu.au KAI TANG, Senior Research Scientist, is with the SINTEF Materials and Chemistry, 7465 Trondheim, Norway. OLEG OSTROVSKI, Emeritus Professor, is with the School of Materials Science and Engineering, University of New South Wales, Sydney, NSW 2052, Australia. RAGNAR TRONSTAD, Director R\&D, is with the School of Materials Science and Engineering, University of New South Wales, Sydney, NSW 2052, Australia.

Manuscript submitted January 27, 2015. in 1892 using a process known as the Acheson method. In this process, $\mathrm{SiC}$ was produced by the reaction between silica sand and petroleum coke at very high temperature (above $\left.2773 \mathrm{~K}\left(2500{ }^{\circ} \mathrm{C}\right)\right)^{[6,7]}$ However, this reaction proceeds slowly due to inadequate contact between the solid particles. A much faster process involves a direct carburization of metallic silicon by combustion synthesis (self-propagating). ${ }^{[8,9]}$ However, this method is expensive because of the cost of elemental silicon. $\mathrm{SiC}$ can also be produced by gaseous pyrolysis of silane $\left(\mathrm{SiH}_{4}\right)^{[10,11]}$ or methylchlorosilane $\left(\mathrm{CH}_{3} \mathrm{SiCl}_{3}\right)^{[12]}$ in a carbon-containing atmosphere (chemical vapor deposition technique). This process is not only expensive, but also very corrosive. Therefore, development of a new, efficient process for synthesis of $\mathrm{SiC}$ is of high importance.

A carbothermal reduction process requires intimate contact between a solid oxide and a carbonaceous material. Intensive researches have been conducted in the production of various metal carbides using methane. Ostrovski and Zhang ${ }^{[13-18]}$ investigated the reduction and carburization of the oxides of iron, manganese, chromium, and titanium by $\mathrm{CH}_{4}-\mathrm{H}_{2}-\mathrm{Ar}$ gas mixtures. Methane-containing gas with high carbon activity (above unity relative to graphite) provided strongly reducing conditions, in which metal oxides were reduced and carburized to metal carbides. Iron oxide was first reduced to metallic iron by hydrogen and then carburized to cementite $\mathrm{Fe}_{3} \mathrm{C}^{[17,18]}$ Manganese oxide was reduced to carbide $\mathrm{Mn}_{7} \mathrm{C}_{3}$ through the sequence: $\mathrm{MnO}_{2} \rightarrow \mathrm{Mn}_{2} \mathrm{O}_{3} \rightarrow \mathrm{Mn}_{3} \mathrm{O}_{4} \rightarrow \mathrm{MnO} \rightarrow$ $\mathrm{Mn}_{7} \mathrm{C}_{3}{ }^{[15]}$; and Rutile was reduced to titanium oxycarbide in the following sequence: $\mathrm{TiO}_{2} \rightarrow \mathrm{Ti}_{5} \mathrm{O}_{9} \rightarrow \mathrm{Ti}_{4} \mathrm{O}_{7} \rightarrow$ $\mathrm{Ti}_{3} \mathrm{O}_{5} \rightarrow \mathrm{Ti}_{2} \mathrm{O}_{3} \rightarrow \mathrm{TiO}_{x} \mathrm{C}_{y}{ }^{[14]}$

Lee et al. ${ }^{[19]}$ implemented a thermodynamic analysis of carbothermal formation of $\mathrm{SiC}$ and elemental $\mathrm{Si}$. 
They demonstrated that methane decomposes completely at temperatures above $1250{ }^{\circ} \mathrm{C}$. In a practical process, a thermodynamic equilibrium state is not immediately reached, so inclusion of highly reactive methane in a high-temperature reaction system can improve the reaction kinetics as demonstrated by reduction of other metal oxides. However, no experimental investigations have been reported in literature on the direct reduction of $\mathrm{SiO}_{2}$ to $\mathrm{SiC}$ by methane-containing gas. Our experimental study of direct reduction of quartz or amorphous silica powder by methane demonstrated that intermediate product $\mathrm{SiO}$ vapor escaped from the reaction zone as fume during reaction without conversion to $\mathrm{SiC}$. This problem is not encountered in reduction of other metal oxides by methane as their intermediates are in the form of metals $\left(\mathrm{Fe}^{[17,18]}\right)$ or solid suboxides $\left(\mathrm{Mn}_{x} \mathrm{O}_{y}{ }^{[15]}\right.$ and $\left.\mathrm{Ti}_{x} \mathrm{O}_{y}{ }^{[14]}\right)$ which are further converted to metal carbides by reacting with methane or deposited carbon. The gaseous $\mathrm{SiO}$ can be "caught" providing an intimate contact of quartz with solid carbon either by chemical vapor deposition from methane in silica particles before reduction ${ }^{[20]}$ or by mechanical mixing of carbon and silica. ${ }^{[21-23]}$

This work presents an investigation of synthesis of $\mathrm{SiC}$ by the carbothermal reduction of quartz in $\mathrm{CH}_{4}$ $\mathrm{H}_{2}-\mathrm{Ar}$ gas mixtures. The reactant pellet is a quartzgraphite mixture with $\mathrm{C} / \mathrm{SiO}_{2}$ molar ratio of 2 which is less than the stoichiometric ratio for $\mathrm{SiC}$ production $\left(\mathrm{C} / \mathrm{SiO}_{2}=3\right)$. Methane is expected to substitute partial reductant graphite and enhance the reduction rate. The main objective of this study was to establish the mechanism of carbothermal reduction of quartz in the $\mathrm{CH}_{4}-\mathrm{H}_{2}-\mathrm{Ar}$ gas mixture under strongly irreversible conditions.

\section{EXPERIMENTAL}

Quartz powder (particle size $<70 \mu \mathrm{m}$ ) was obtained by crushing quartz lumps in a 6-inch agate pulveriser in a Rocklabs ring mill. The agate was made of gray silica so that contamination to the quartz sample was minimized. The contents of impurities in quartz lumps were presented elsewhere. ${ }^{[24]}$ Quartz powder and synthetic graphite $(\geq 99.99$ pct, $<45 \mu \mathrm{m}$, Sigma-Aldrich Co. Ltd., Germany) were mixed with distilled water ( $80 \mathrm{wt}$ pct of solid mixture) in a plastic jar with zirconia balls for 8 hours. The quartz-graphite mixture had a $\mathrm{C} / \mathrm{SiO}_{2} \mathrm{mo}-$ lar ratio of 2.0. This ratio was below the stoichiometric ratio $3: 1$ needed for complete conversion of quartz to SiC. Carbon deficit was covered by methane. Reduction of quartz with $\mathrm{C} / \mathrm{SiO}_{2}=3$ was also examined for comparison. Water was removed by heating the mixture at $393 \mathrm{~K}\left(120^{\circ} \mathrm{C}\right)$ for 48 hours. Then the mixture was pressed into pellets in a uniaxial hydraulic press by applying $20 \mathrm{KN}$ of load for 2 minutes. The pellets with a mass of approximately $1 \mathrm{~g}$ were $8 \mathrm{~mm}$ in diameter and about $12 \mathrm{~mm}$ in height.

Reduction experiments were carried out in a laboratory fixed-bed reactor heated in a vertical tube electric furnace. The reactor setup was presented previously. ${ }^{[24]}$
A weighed pellet was loaded at the bottom of the reactor and then heated to the desired temperature by inserting the reactor into the furnace, so that the sample was located in the furnace hot zone. Reduction was studied in $\mathrm{CH}_{4}-\mathrm{H}_{2}-\mathrm{Ar}$ gas mixtures of different compositions which were formed by mixing individual gasses of 99.999 wt pet purity. The gas flow rates were controlled by mass flow controllers. The total gas flow rate was maintained at $1.00 \mathrm{NL} / \mathrm{min}$. The outlet gas composition was continuously monitored by an infrared $\mathrm{CO} / \mathrm{CO}_{2} /$ $\mathrm{CH}_{4}$ analyzer (Advanced optima AO2020, ABB Ltd., Ladenburg, Germany) connected with a computer. Data of gas concentrations were recorded every 5 seconds. Reaction was stopped after certain duration by raising the reactor above the furnace hot zone and cooling down. After that, the reduced pellet was weighed and subjected to characterization.

The original mixture and reduced samples were analyzed by X-ray diffraction (XRD, MMA, GBC Scientific Equipment, Braeside, Australia). The fine powder of a sample after grinding was scanned at a speed of $0.02 \mathrm{deg} \mathrm{s}^{-1}$ and step size $0.02 \mathrm{deg}$ with $\mathrm{CuK}$ radiation generated at $35 \mathrm{kV}$ and $28.6 \mathrm{~mA}$.

The morphology of the samples was investigated by field-emission scanning electron microscopy (FESEM, JSM-6000, JEOL, Tokyo, Japan) operated at $15 \mathrm{KV}$.

The oxygen content of the reduced samples was determined by LECO Nitrogen/Oxygen Determinator (TC-436 DR, St. Joseph). A weighed sample was loaded into a tin crucible and then a nickel basket. A graphite crucible was placed between two electrodes. High current passed through this crucible heating it up to temperatures above $3100{ }^{\circ} \mathrm{C}$. After an outgassing procedure, the nickel basket containing a sample was dropped into the graphite crucible from a loading head purged by helium. At the high temperature, oxygen from the sample combined with the carbon of the crucible to form carbon monoxide (CO) and carbon dioxide $\left(\mathrm{CO}_{2}\right)$ which were detected by infrared detectors. The instrument was calibrated using standard samples with appropriate oxygen contents.

The contents of free carbon in samples were determined by Carbon/Sulfur Determinator (CS-2000, ELTRA Elemental Analyzers, Haan, Germany). A weighed sample was placed into a ceramic crucible. The system was closed and purged with oxygen. The crucible was heated in a resistance furnace with fixed temperature of $1213 \mathrm{~K}\left(940{ }^{\circ} \mathrm{C}\right)$ in oxygen atmosphere. Free carbon from the sample reacts with oxygen to form $\mathrm{CO}$ and $\mathrm{CO}_{2}$ which were analyzed by infrared detectors. The instrument was calibrated using standard samples with appropriate carbon contents.

The equilibrium phases in the system of carbothermal reduction of quartz were calculated using Outokumpu HSC Chemistry software (Version 6.1, Outokumpu Research Oy, Pori, Finland).

The extent of reduction was defined as the fraction of oxygen in quartz removed in the course of reduction. Oxygen was removed in the form of $\mathrm{CO}, \mathrm{CO}_{2}$, and $\mathrm{SiO}$. The main oxygen-containing compound in gas phase was $\mathrm{CO}$, as $\mathrm{CO}_{2}$ was converted to $\mathrm{CO}$ by the Boudouard reaction, and $\mathrm{SiO}$ reacted with graphite forming $\mathrm{SiC}$. 
Using the $\mathrm{CO}$ and $\mathrm{CO}_{2}$ concentrations in the off gas, the extent of reduction was calculated using Eq. [2]:

$$
X^{\prime}=\frac{1}{n_{\mathrm{O}-\mathrm{i}}} \int_{0}^{t} \frac{F}{22.4}\left(C_{\mathrm{V}-\mathrm{CO}}+2 \times C_{\mathrm{V}-\mathrm{CO}_{2}}\right) \mathrm{d} t,
$$

where $X^{\prime}$ is the conversion of silica based on $\mathrm{CO}$ and $\mathrm{CO}_{2}$ concentrations, pct at time $t ; C_{\mathrm{V}-\mathrm{CO}}$ is the concentration of $\mathrm{CO}$ and $C_{\mathrm{V}-\mathrm{CO}_{2}}$ the concentration of $\mathrm{CO}_{2}$, vol pct; $F$ is the gas flow rate, NL/min; $n_{\mathrm{O}-\mathrm{i}}$ is the initial content of oxygen in quartz, mol; and $t$ is the reaction time, minute.

More accurate value of $\mathrm{X}$ was obtained using a residual oxygen content in the reacted sample derived from the LECO oxygen analysis. In this case, the conversion of $\mathrm{SiO}_{2}$ can be simply presented as

$$
X=\frac{1}{n_{\mathrm{O}-\mathrm{i}}}\left(n_{\mathrm{O}-\mathrm{i}}-n_{\mathrm{O}-\mathrm{LECO}}\right) \times 100,
$$

where $X$ is the conversion of silica at the end of reduction, pct; and $n_{\text {O-LECO }}$ is the content of oxygen in the reacted sample, mol.

Plots of the extent of reduction $X v s$ the reaction time $\mathrm{t}$ were obtained by normalizing the final extent of reduction from on-line gas analysis ( $X^{\prime}$ from Eq. [2]) to the values determined using LECO analyzer. The error of measured oxygen content by LECO analysis depends on the residual oxygen content in the reduced sample. For a sample with the extent of reduction of 90 pct, the error of oxygen analysis was about 0.1 pct, which gives an error in the extent of reduction of 0.3 pct. Including other errors such as in weighing and gas flow rate, the overall error of the final extent of reduction is estimated to be less than 1 pct.

Assuming that reduced samples consisted of $\mathrm{SiC}$, $\mathrm{SiO}_{2}$, and free carbon, the yield of $\mathrm{SiC}$ (percentage of silicon in an original sample converted to $\mathrm{SiC}$ ) was calculated using the following equation:

$$
Y_{\mathrm{SiC}}=\frac{100}{40 \times n_{\mathrm{Si}}} \times m \times\left(1-C_{\mathrm{C}-\mathrm{LECO}}-C_{\mathrm{O}-\mathrm{LECO}} \times 60 / 32\right),
$$

where $n_{\mathrm{Si}}$ is the initial amount of $\mathrm{SiO}_{2}$ in pellet before reduction, mol; $\mathrm{m}$ is the weight of pellet after reduction, g; and $C_{\mathrm{C}-\mathrm{LECO}}$ and $C_{\mathrm{O}-\mathrm{LECO}}$ are the mass contents of free carbon and oxygen in the reduced sample, respectively, pct.

During reduction, the part of generated $\mathrm{SiO}$ blown out from the pellet was defined as loss of silicon as $\mathrm{SiO}$ and calculated using Eq. [5]:

$$
Y_{\mathrm{SiO}}=\frac{1}{n_{\mathrm{Si}}} \times\left[n_{\mathrm{Si}} \times\left(100-Y_{\mathrm{SiC}}\right)-m \times C_{\mathrm{O}-\mathrm{LECO}} / 32\right] .
$$

\section{RESULTS}

\section{A. Effect of Temperature}

The effect of temperature on the reduction of quartz was studied in the temperature range of $1573 \mathrm{~K}$ to

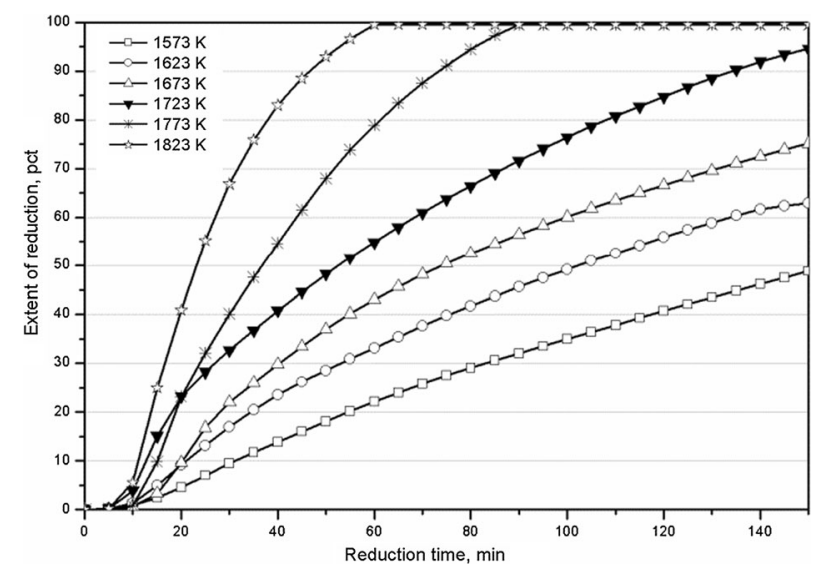

Fig. 1-Effect of temperature on the extent of reduction in 1 vol pct $\mathrm{CH}_{4}-70$ vol pet $\mathrm{H}_{2}-29$ vol pet Ar gas mixture.

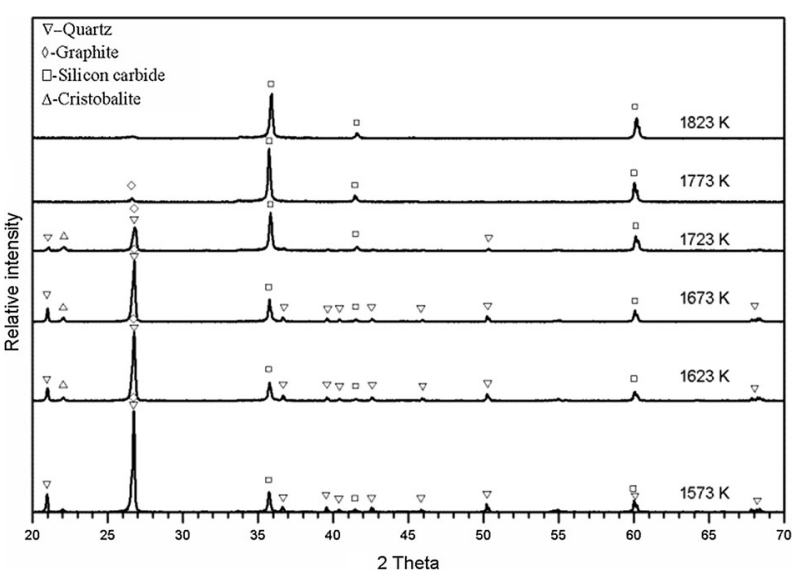

Fig. 2-XRD patterns of samples reduced in 1 vol pet $\mathrm{CH}_{4}-70$ vol pct $\mathrm{H}_{2}-29$ vol pct $\mathrm{Ar}$ gas mixture at different temperatures for $150 \mathrm{~min}$.

$1823 \mathrm{~K}\left(1300{ }^{\circ} \mathrm{C}\right.$ to $\left.1550{ }^{\circ} \mathrm{C}\right)$. The inlet gas mixture contained 1 vol pct of methane, 70 vol pct of hydrogen, and 29 vol pct of argon. The extent of reduction vs time at different temperatures is shown in Figure 1. Figure 2 presents the XRD spectra of samples reduced for 150 minutes. Table I lists the final extent of reduction and yield of $\mathrm{SiC}$ after 150-minute reduction.

At $1573 \mathrm{~K}\left(1300{ }^{\circ} \mathrm{C}\right)$, carbothermal reduction of quartz was slow, reaching an extent of reduction of 48.8 pct after 150 minutes. A small amount of $\beta$-SiC was identified in the reduction product, corresponding to the weak peaks at $2 \theta=35.66(d=2.5161 \AA)$, $2 \theta=41.40 \quad(d=2.1790 \AA)$, and $2 \theta=59.99(d=$ $1.5408 \AA$ ). The yield of $\mathrm{SiC}$ was 38.5 pet as shown in Table I. With the increase of temperature, the rate of reduction and the composition of reduced samples changed consistently. In reduction at $1773 \mathrm{~K}\left(1500{ }^{\circ} \mathrm{C}\right)$, the oxygen content decreased to $0.49 \mathrm{wt}$ pct, and free carbon content was $3.67 \mathrm{wt}$ pct. Corresponding extent of reduction was 99.5 pct which did not increase further with the extension of reduction time. The yield of $\mathrm{SiC}$ was $72.4 \mathrm{pct}$; a significant fraction of silicon in the raw 
Table I. Extent of Reduction and Yield of SiC After Carbothermal Reduction in $\mathrm{CH}_{4}-\mathrm{H}_{2}-\mathrm{Ar}$ Gas Mixture at Different Temperatures for $150 \mathrm{~min}$

\begin{tabular}{lllllll}
\hline Temperature $\left[\mathrm{K}\left({ }^{\circ} \mathrm{C}\right)\right]$ & $1573(1300)$ & $1623(1350)$ & $1673(1400)$ & $1723(1450)$ & $1773(1500)$ & $1823(1550)$ \\
Free carbon content (wt pct) & 26.5 & 23.2 & 18.3 & 11.4 & 3.67 & 4.25 \\
Oxygen content (wt pct) & 26.9 & 22.9 & 20.0 & 11.5 & 0.49 & 0.50 \\
Weight loss (pct) & 20.4 & 24.5 & 33.0 & 51.6 & 63.9 & 62.9 \\
Loss of Si as SiO (mol pct) & 5.27 & 0.93 & 2.69 & 17.2 & 27.2 & 26.6 \\
Extent of reduction (pct) & 48.8 & 62.9 & 75.1 & 94.6 & 99.5 & 99.6 \\
Yield of SiC (pct) & 38.5 & 53.8 & 62.1 & 68.2 & 72.4 & 73.0 \\
\hline
\end{tabular}

material was lost as $\mathrm{SiO}$ which will be discussed in Section IV. Further increase in temperature to $1773 \mathrm{~K}$ and $1823 \mathrm{~K}\left(1500{ }^{\circ} \mathrm{C}\right.$ and $\left.1550{ }^{\circ} \mathrm{C}\right)$ accelerated the reduction but no effect on the extent of reduction, which was close to completion at these temperatures.

In addition to quartz, cristobalite peaks were detected in the samples reduced at $1623 \mathrm{~K}, 1673 \mathrm{~K}$, and $1723 \mathrm{~K}$ $\left(1350{ }^{\circ} \mathrm{C}, 1400{ }^{\circ} \mathrm{C}\right.$, and $1450{ }^{\circ} \mathrm{C}$ ), as a result of the transformation of quartz to cristobalite at high temperatures. ${ }^{[25]}$ Neither quartz nor cristobalite was detected in the samples reduced at $1773 \mathrm{~K}$ and $1823 \mathrm{~K}\left(1500{ }^{\circ} \mathrm{C}\right.$ and $1550{ }^{\circ} \mathrm{C}$ ).

\section{B. Effect of Methane Content in the Gas Mixture}

The effect of methane content in the gas mixture on the carbothermal reduction of quartz was examined in the range of 0 to $6 \mathrm{vol}$ pct, maintaining hydrogen content at 70 vol pet and temperature at $1773 \mathrm{~K}$ $\left(1500{ }^{\circ} \mathrm{C}\right)$. The extent of reduction $v s$ time for different methane contents is shown in Figure 3. The XRD spectra of samples after reduction are presented in Figure 4. Table II presents the characterization of the samples after 150-minute reduction. During reduction without addition of methane, the weight loss was 79.4 pct, while the extent of reduction was 85.0 pct. Graphite in the original mixture was almost consumed completely by the carbothermal reduction; graphite peaks were not detected by the XRD analysis of the reduced sample. The $\mathrm{SiC}$ yield was only 42.6 pct. Addition of 0.5 pet methane in the gas mixture remarkably increased reduction rate, resulting in the decrease in weight loss to $69.0 \mathrm{pct}$, and the increase in the extent of reduction and $\mathrm{SiC}$ yield to 99.3 and $62.8 \mathrm{pct}$, correspondingly. Further increasing methane content to $1 \mathrm{vol}$ pct resulted in a slight further increase in the reduction rate; however, the $\mathrm{SiC}$ yield increased by approximately 10 pct. There was an insignificant increase in the content of free carbon in the reduced samples. When the methane content further increased to 2 vol pct, the reduction rate was barely changed. The extent of reduction was slightly decreased, while the yield of $\mathrm{SiC}$ marginally increased. A marked change was the free carbon content in the reduced sample which increased to 10.1 pct. This is an indication of thermal cracking of methane. Further increasing the concentration of methane in the gas mixture, although had a small effect on the initial rate of reduction, resulted in significant suppression of the reduction at the later stage, resulting in a sharp decrease in the weight loss, extent of reduction, and the yield of SiC. The content of free

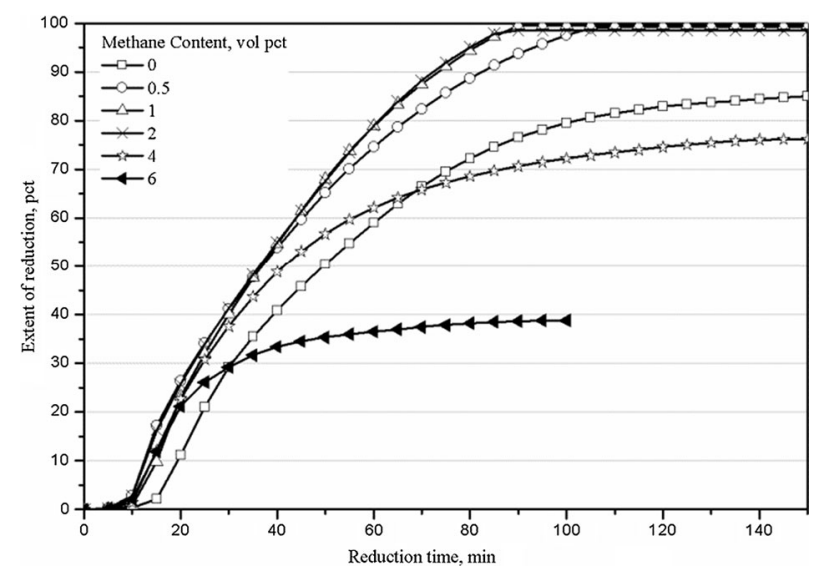

Fig. 3-Effect of methane content in $\mathrm{CH}_{4}-\mathrm{H}_{2}-\mathrm{Ar}$ gas mixtures on the extent of reduction at $1773 \mathrm{~K}\left(1500{ }^{\circ} \mathrm{C}\right)$.



Fig. 4-XRD patterns of samples reduced in $\mathrm{CH}_{4}-\mathrm{H}_{2}-\mathrm{Ar}$ gas mixtures with different methane contents at $1773 \mathrm{~K}\left(1500^{\circ} \mathrm{C}\right)$ for $150 \mathrm{~min}$.

carbon in the samples reduced in the gas mixture containing 6 pct methane increased to 32.0 pct reflecting the strong effect of the methane cracking on the reduction of silica.

\section{Effect of Hydrogen Content in the Gas Mixture}

The effect of hydrogen content in the gas mixture on the carbothermal reduction of quartz was examined at $1773 \mathrm{~K}\left(1500{ }^{\circ} \mathrm{C}\right)$ with a constant methane concentration of 1 vol pct. The hydrogen content in the gas mixture was varied from 0 to 99 vol pct. Figure 5 
Table II. Extent of Reduction and Yield of SiC After Carbothermal Reduction at $1773 \mathrm{~K}\left(1500{ }^{\circ} \mathrm{C}\right)$ in the $\mathrm{CH}_{4}-\mathrm{H}_{2}-\mathrm{Ar} \mathrm{Gas}^{\mathrm{Mix}-}$ tures with Different Methane Contents for 150 min

\begin{tabular}{|c|c|c|c|c|c|c|}
\hline$\overline{\text { Methane content (vol pct) }}$ & $\overline{0}$ & 0.5 & 1.0 & 2.0 & 4.0 & $6.0^{*}$ \\
\hline Free carbon content (wt pct) & 0.12 & 1.68 & 3.67 & 10.1 & 28.2 & 32.0 \\
\hline Oxygen content (wt pct) & 0.94 & 0.91 & 0.49 & 1.64 & 19.5 & 27.3 \\
\hline Weight loss (pct) & 79.4 & 69.0 & 63.9 & 58.1 & 28.1 & 13.2 \\
\hline Loss of $\mathrm{Si}$ as $\mathrm{SiO}$ (mol pct) & 56.9 & 36.4 & 27.2 & 25.0 & 10.0 & 7.22 \\
\hline Extent of reduction (pct) & 85.0 & 99.3 & 99.5 & 98.5 & 76.2 & 38.8 \\
\hline Yield of $\mathrm{SiC}(\mathrm{pct})$ & 42.6 & 62.8 & 72.4 & 73.3 & 53.1 & 30.5 \\
\hline
\end{tabular}

*The reduction proceeded for $100 \mathrm{~min}$.

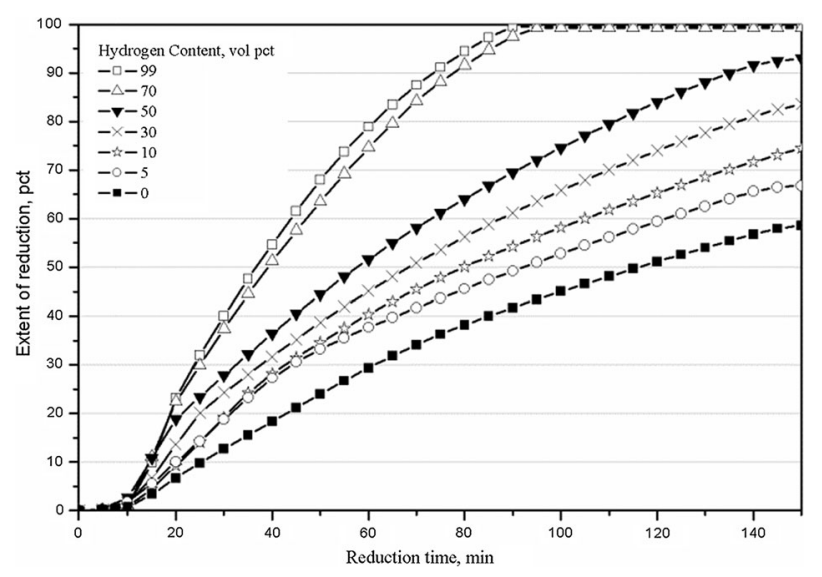

Fig. 5-Effect of hydrogen content in $\mathrm{CH}_{4}-\mathrm{H}_{2}-\mathrm{Ar}$ gas mixtures on the extent of reduction at $1773 \mathrm{~K}\left(1500^{\circ} \mathrm{C}\right)$.

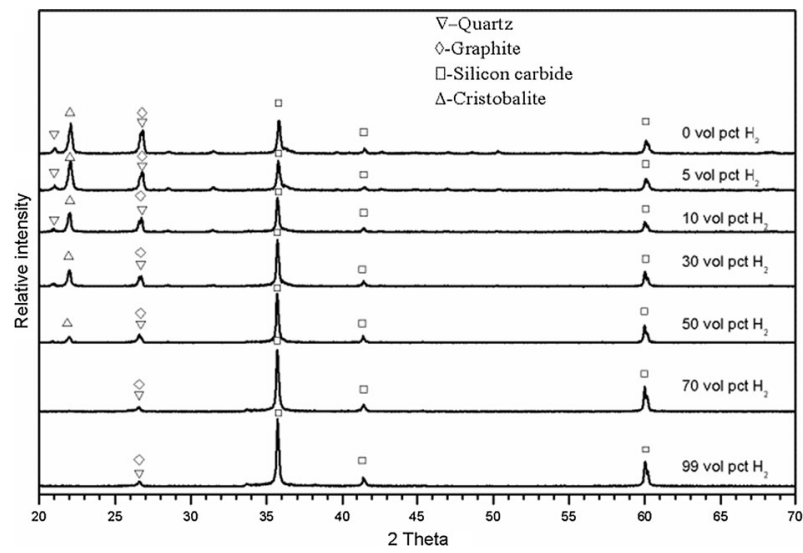

Fig. 6-XRD patterns of samples reduced in $\mathrm{CH}_{4}-\mathrm{H}_{2}-\mathrm{Ar}$ gas mixtures with different hydrogen contents at $1773 \mathrm{~K}\left(1500^{\circ} \mathrm{C}\right)$ for $150 \mathrm{~min}$.

depicts the progress of reduction $v s$ time for different hydrogen contents, and Figure 6 presents the XRD patterns of samples after reduction for 150 minutes. Table III presents the final extent of reduction and yield of $\mathrm{SiC}$ after 150-minute reduction. Increase in the hydrogen concentration in the reducing gas in the range of 0 to $70 \mathrm{vol}$ pet strongly increased the extent of reduction and yield of $\mathrm{SiC}$ and did not show further visible enhancing effect on the reduction in the range of 70 to $99 \mathrm{vol}$ pct. The content of free carbon decreased from $27.3 \mathrm{wt}$ pct when the gas mixture contained no hydrogen to $3.67 \mathrm{wt}$ pct when hydrogen content was 70 vol pct.

\section{DISCUSSION}

Reduction of quartz by carbon described by Reaction [1] is a combination of Reactions [6] and [7]:

$$
\begin{aligned}
\mathrm{SiO}_{2}(\mathrm{~s})+\mathrm{C}(\mathrm{s}) & =\mathrm{SiO}(\mathrm{g})+\mathrm{CO}(\mathrm{g}) \\
\Delta G^{\circ} & =668.07-0.3288 T(\mathrm{~kJ}) \\
\mathrm{SiO}(\mathrm{g})+2 \mathrm{C}(\mathrm{s}) & =\mathrm{SiC}(\mathrm{s})+\mathrm{CO}(\mathrm{g}) \\
\Delta G^{\circ} & =-78.891+0.001 T(\mathrm{~kJ})
\end{aligned}
$$

The reactions generate both $\mathrm{SiC}$ and $\mathrm{SiO}$ of which amounts depend on the carbon-to-quartz ratio $x$. When $1<x<3$,

$$
\begin{aligned}
\mathrm{SiO}_{2}(\mathrm{~s})+x \mathrm{C}(\mathrm{s})= & (x-1) / 2 \mathrm{SiC}(\mathrm{s})+(3-x) / 2 \mathrm{SiO}(\mathrm{g}) \\
& +(1+x) / 2 \mathrm{CO}(\mathrm{g}) .
\end{aligned}
$$

Schei and Halvorsen ${ }^{[26]}$ defined $x$ in Reaction [8] as carbon coverage. Reaction [8] indicates that when $\mathrm{C} /$ $\mathrm{SiO}_{2}$ molar ratio is less than a stoichiometric ratio of 3 , silicon can be lost in the form of $\mathrm{SiO}(\mathrm{g})$ which is blown out of the reactor. The SiC recovery depends on the carbon coverage. Introduction of methane to the reaction system with $\mathrm{C} / \mathrm{SiO}_{2}=2$ enhances the formation of $\mathrm{SiC}$ :

$$
\begin{aligned}
& \mathrm{SiO}_{2}(\mathrm{~s})+2 \mathrm{C}(\mathrm{s})+y \mathrm{CH}_{4}(\mathrm{~g})=(0.5+0.5 y) \mathrm{SiC}(\mathrm{s}) \\
& \quad+(0.5-0.5 y) \mathrm{SiO}(\mathrm{g})+(1.5+0.5 y) \mathrm{CO}(\mathrm{g})+2 y \mathrm{H}_{2}(\mathrm{~g})
\end{aligned}
$$

Along with increasing $y(y \leq 1)$, the yield of $\mathrm{SiC}$ increases. Complete conversion of silica to $\mathrm{SiC}$ theoretically can be reached at $y=1$.

Figure 7 presents the calculated equilibrium compositions in the carbothermal reduction of quartz with and without methane addition. To reduce the $\mathrm{CO}$ partial pressure, $1 \mathrm{~mol}$ of argon was added to the reaction systems. In the system containing $1 \mathrm{~mol} \mathrm{SiO}_{2}, 2 \mathrm{~mol} \mathrm{C}$, and $1 \mathrm{~mol}$ argon (Figure 7(a)), reduction of $\mathrm{SiO}_{2}$ starts at $1373 \mathrm{~K}\left(1100{ }^{\circ} \mathrm{C}\right)$; carbothermal reduction of $\mathrm{SiO}_{2}$ proceeds until $1773 \mathrm{~K}\left(1500{ }^{\circ} \mathrm{C}\right)$ at which all carbon is used up. Further increasing temperature results in the reduction of $\mathrm{SiO}_{2}$ by $\mathrm{SiC}$ with evolution 
Table III. Extent of Reduction and Yield of SiC After Carbothermal Reduction at $1773 \mathrm{~K}\left(1500{ }^{\circ} \mathrm{C}\right)$ in the $\mathrm{CH}_{4}-\mathrm{H}_{2}-\mathrm{Ar} \mathrm{Gas}$ Mixtures with Different Hydrogen Contents for $150 \mathrm{~min}$

\begin{tabular}{|c|c|c|c|c|c|c|c|}
\hline Hydrogen content (vol pct) & 0 & 5 & 10 & 30 & 50 & 70 & 99 \\
\hline Free carbon content (wt pct) & 27.3 & 24.1 & 17.7 & 11.4 & 8.67 & 3.67 & 3.05 \\
\hline Oxygen content (wt pct) & 21.0 & 18.0 & 15.0 & 11.0 & 3.26 & 0.49 & 0.23 \\
\hline Weight loss (pct) & 35.2 & 41.2 & 48.3 & 55.5 & 60.5 & 63.9 & 64.3 \\
\hline Loss of $\mathrm{Si}$ as $\mathrm{SiO}$ (mol pct) & 18.9 & 20.1 & 20.7 & 23.7 & 25.9 & 27.2 & 27.3 \\
\hline Extent of reduction (pct) & 58.6 & 66.8 & 74.5 & 83.5 & 93.0 & 99.5 & 99.6 \\
\hline Yield of SiC (pct) & 45.5 & 52.1 & 58.9 & 63.5 & 70.7 & 72.4 & 72.5 \\
\hline
\end{tabular}

of $\mathrm{SiO}$ vapor by Reaction [10]. $\mathrm{SiO}_{2}$ is fully reacted when the temperature is increased to $2223 \mathrm{~K}\left(1950^{\circ} \mathrm{C}\right)$.

$$
\begin{aligned}
2 \mathrm{SiO}_{2}(\mathrm{~s})+\mathrm{SiC}(\mathrm{s}) & =3 \mathrm{SiO}(\mathrm{g})+\mathrm{CO}(\mathrm{g}) \\
\Delta G^{\circ} & =1444.3-0.6700 T(\mathrm{~kJ})
\end{aligned}
$$

When $1 \mathrm{~mol}$ of methane is added to the system (Figure 7(b)), decomposition of methane takes place before the reduction of $\mathrm{SiO}_{2}$ starts at $1293 \mathrm{~K}\left(1020^{\circ} \mathrm{C}\right)$; conversion of $\mathrm{SiO}_{2}$ is completed at $1893 \mathrm{~K}\left(1620^{\circ} \mathrm{C}\right)$. Quartz is predominantly reduced to $\mathrm{SiC}$; evolution of $\mathrm{SiO}$ is negligible in the course of reduction which means that there is no significant loss of silicon. The same effect can be achieved by increasing the amount of carbon in the system to $\mathrm{C} / \mathrm{SiO}_{2}=3$ (Figure 7(c)).

However, the experimental data were quite different from results of thermodynamic calculations. The studied reaction system with continuously flowing gas was not in the batch operation as in the thermodynamic modeling. $\mathrm{CO}$ formed by reduction was continuously removed from the reactor, what greatly enhanced the reduction process. On the other hand, $\mathrm{SiO}$ diffused out of the pellets and was flushed out of the reactor with a significant loss of silicon as $\mathrm{SiO}$ and decrease in the $\mathrm{SiC}$ yield.

Figure 8 presents the rate of generation of $\mathrm{CO}$ in carbothermal reduction of quartz with molar $\mathrm{C} / \mathrm{SiO}_{2}=2$ in argon and $\mathrm{CH}_{4}-\mathrm{H}_{2}-\mathrm{Ar}$ gas mixture, and molar $\mathrm{C} / \mathrm{SiO}_{2}=3$ in argon and hydrogen at $1773 \mathrm{~K}$ $\left(1500{ }^{\circ} \mathrm{C}\right)$. Reduction of quartz with $\mathrm{C} / \mathrm{SiO}_{2}=3$ was faster than that with $\mathrm{C} / \mathrm{SiO}_{2}=2$ in argon, but it was not completed in 150 minutes. Reduction of quartz in the $\mathrm{CH}_{4}-\mathrm{H}_{2}-\mathrm{Ar}$ gas mixture was much faster than that in argon and was completed in 116 minutes. In the main period of reduction time, reduction of quartz with $\mathrm{C} / \mathrm{SiO}_{2}=2$ in $\mathrm{CH}_{4}-\mathrm{H}_{2}-\mathrm{Ar}$ gas mixture was faster than with $\mathrm{C} / \mathrm{SiO}_{2}=3$ in hydrogen, which is attributed to high carbon activity in the $\mathrm{CH}_{4}-\mathrm{H}_{2}-\mathrm{Ar}$ gas mixture.

Table IV compares the composition of four samples reduced at $1773 \mathrm{~K}\left(1500^{\circ} \mathrm{C}\right)$ for 150 minutes. Increasing carbon content in the $\mathrm{C}-\mathrm{SiO}_{2}$ mixture decreased the loss of $\mathrm{Si}$ as $\mathrm{SiO}$ during reduction in argon. Reduction of quartz with $\mathrm{C} / \mathrm{SiO}_{2}=3$ in hydrogen enhanced the extent of reduction of quartz and the yield of $\mathrm{SiC}$, but the loss of $\mathrm{Si}$ as $\mathrm{SiO}$ was pretty high, 33.8 pct. Partial replacement of carbon by methane in the gas phase made the reduction close to completion, decreased the loss of $\mathrm{SiO}$, and increased the $\mathrm{SiC}$ yield in the carbothermal reduction of silica.

When carbothermal reduction of quartz occurred in the gas mixture with low-concentration methane $(0.5$ to 2 vol pct), reaction rate increased significantly. The yield of $\mathrm{SiC}$ also increased due to the high reduction rate.

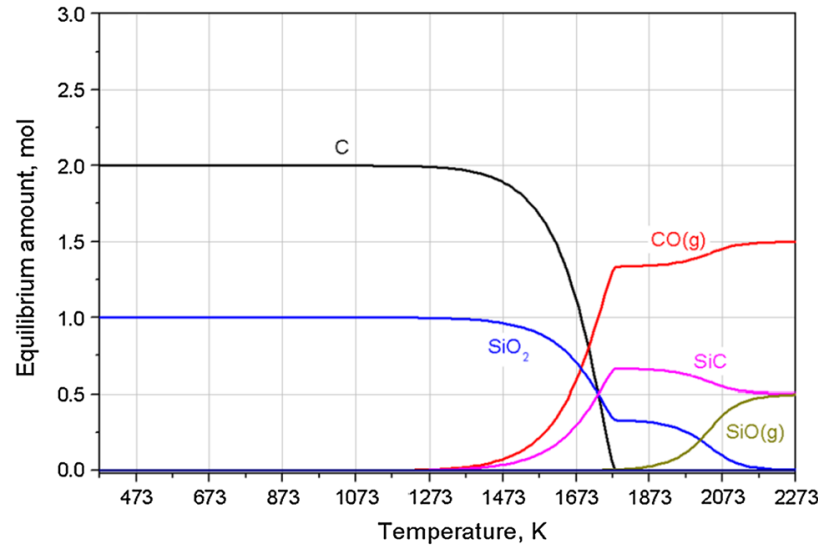

(a)

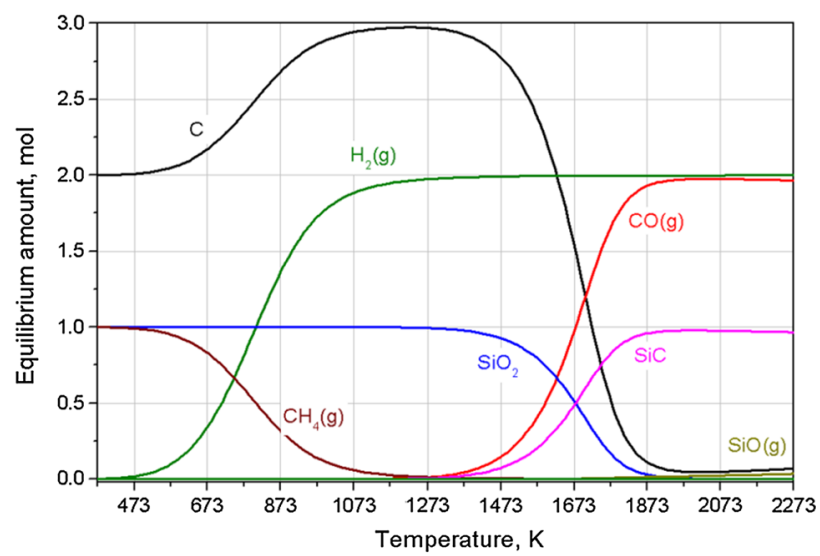

(b)

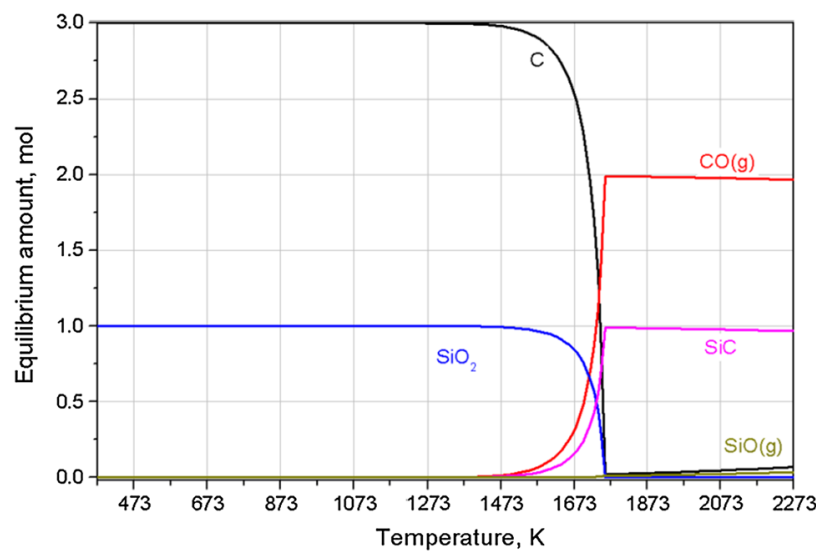

(c)

Fig. 7-Equilibrium compositions of the systems: (a) $1 \mathrm{~mol} \mathrm{SiO}_{2}+2$ mol C +1 mol Ar; (b) $1 \mathrm{~mol} \mathrm{SiO}_{2}+2 \mathrm{~mol} \mathrm{C}+1 \mathrm{~mol} \mathrm{CH}_{4}+1 \mathrm{~mol}$ $\mathrm{Ar}$; and (c) $1 \mathrm{~mol} \mathrm{SiO}_{2}+3 \mathrm{~mol} \mathrm{C}+1 \mathrm{~mol} \mathrm{Ar}$ calculated using $\mathrm{HSC}$ Chemistry 6.1. 
Reduction of $\mathrm{SiO}_{2}$ to $\mathrm{SiC}$ by methane can be described by Reactions [11] and [12]:

$$
\begin{aligned}
\mathrm{SiO}_{2}(\mathrm{~s})+\mathrm{CH}_{4}(\mathrm{~g}) & =\mathrm{SiO}(\mathrm{g})+\mathrm{CO}(\mathrm{g})+2 \mathrm{H}_{2}(\mathrm{~g}) \\
\Delta G^{\circ} & =757.07-0.4373 T(\mathrm{~kJ}) \\
\mathrm{SiO}(\mathrm{g})+2 \mathrm{CH}_{4}(\mathrm{~g}) & =\mathrm{SiC}(\mathrm{s})+\mathrm{CO}(\mathrm{g})+4 \mathrm{H}_{2}(\mathrm{~g}) \\
\Delta G^{\circ} & =99.113-0.2160 T(\mathrm{~kJ})
\end{aligned}
$$

In the reduction by methane, it decomposed into reactive carbon species and hydrogen via a series of steps ${ }^{[13]}$ :

$$
\mathrm{CH}_{4}(\mathrm{~g}) \rightarrow \ldots \rightarrow \mathrm{C}_{\mathrm{ad}}+2 \mathrm{H}_{2}(\mathrm{~g}),
$$

in which $\mathrm{C}_{\mathrm{ad}}$ represents active carbon species adsorbed on solid surface; this active carbon is substantially different from deposited solid carbon. The carbon activity in the gas phase can be defined as follows:

$$
\alpha_{C}=K\left(P_{\mathrm{CH}_{4}} / P_{\mathrm{H}_{2}}^{2}\right)
$$

where $K$ is the equilibrium constant of Reaction [14] of methane cracking:

$$
\begin{aligned}
\mathrm{CH}_{4}(\mathrm{~g}) & =\mathrm{C}_{\mathrm{gr}}+2 \mathrm{H}_{2}(\mathrm{~g}) \\
\Delta G^{\circ} & =89.003-0.1085 T(\mathrm{~kJ})
\end{aligned} .
$$

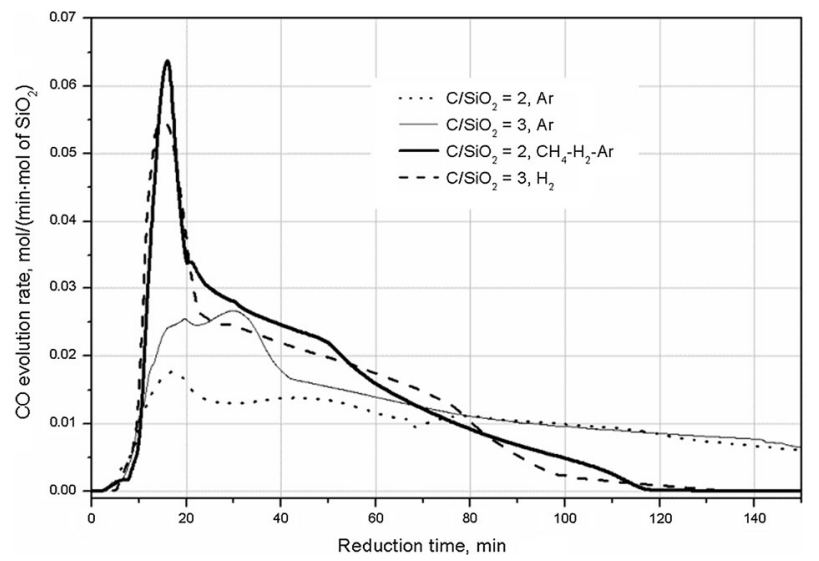

Fig. 8- CO evolution rate in carbothermal reduction at $1773 \mathrm{~K}$ $\left(1500{ }^{\circ} \mathrm{C}\right)$ with changing $\mathrm{C} / \mathrm{SiO}_{2}$ ratios and gas composition. The $\mathrm{CH}_{4}-\mathrm{H}_{2}-\mathrm{Ar}$ gas mixture contained 1 vol pct methane, 70 vol pct hydrogen, and 29 vol pct argon.
In a non-equilibrium system with a tendency of methane cracking, the carbon activity in the gas phase is greater than unity. In the reduction experiments, the $\mathrm{CH}_{4}-\mathrm{H}_{2}-\mathrm{Ar}$ gas mixture is maintained under nonequilibrium conditions with high carbon activity (relative to graphite), as shown in Figure 9. High carbon activity provides a strong thermodynamic driving force for the reduction reaction to proceed.

However, methane cracking and solid carbon deposition rate also increased with increasing methane concentration. Solid carbon deposited on the sample surface by Reaction [15], hindering the further progress of reduction by blocking the particles' surface and preventing carbon supply for further reduction to the pellet's interior.

Therefore, the effect of methane on the carbothermal reduction of quartz was twofold. On one hand, increasing methane content in the gas mixture accelerated reduction and increased the yield of $\mathrm{SiC}$; on the other hand, excess methane content ( $>2$ vol pct) in the gas mixture resulted in the accumulation of solid carbon on the surface of samples and retarded the reactions.

Hydrogen also played an important role in the carbothermal reduction of quartz. Increasing hydrogen content in the gas mixture from 0 to $70 \mathrm{vol}$ pct significantly enhanced the rate and extent of reduction (Figure 5). Hydrogen directly reduced $\mathrm{SiO}_{2}$ to $\mathrm{SiO}$ in the presence of carbon by Reactions [16] and [17]. ${ }^{[27]}$

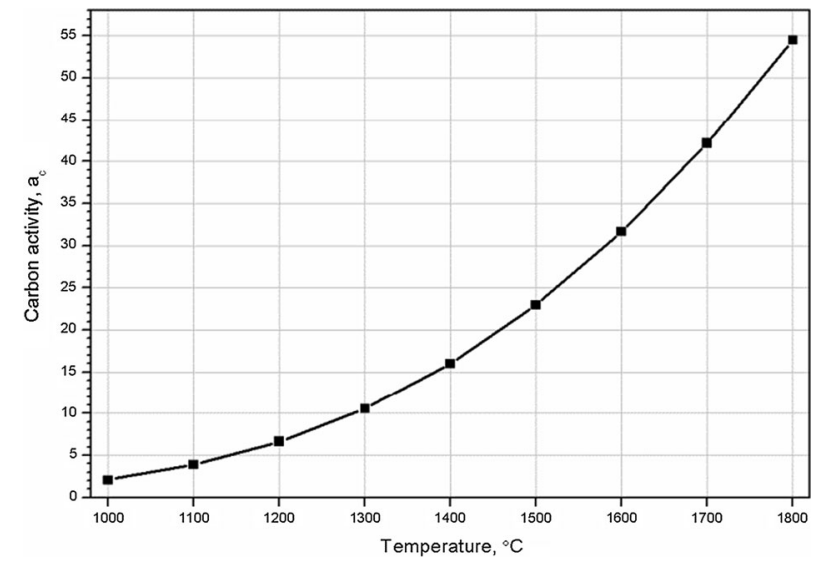

Fig. 9-Carbon activity (relative to graphite) of 1 vol pct $\mathrm{CH}_{4}-70$ vol pet $\mathrm{H}_{2}-29$ vol pet Ar gas mixture.

Table IV. Extent of Carbothermal Reduction of Quartz and Yield of $\mathrm{SiC}$ at $1773 \mathrm{~K}\left(1500{ }^{\circ} \mathrm{C}\right)$ with $\mathrm{Changing}_{\mathrm{C}} / \mathrm{SiO} \mathrm{O}_{2} \mathrm{Ratios}$ and Gas Composition After 150-min Reaction

\begin{tabular}{lllll}
\hline $\mathrm{C} / \mathrm{SiO}_{2}$ molar ratio & 2 & 3 & 2 & 3 \\
Reduction gas atmosphere & $\mathrm{Ar}$ & $\mathrm{Ar}$ & $\mathrm{CH}_{4}-\mathrm{H}_{2}-\mathrm{Ar}^{*}$ & \\
Free carbon content (wt pct) & 0.63 & 10.23 & 3.67 & 0.49 \\
Oxygen content (wt pct) & 20.8 & 16.4 & 63.9 & 0.11 \\
Weight loss (pct) & 65.2 & 58.0 & 27.2 & 0.60 \\
Loss of Si as SiO (mol pct) & 36.9 & 29.9 & 99.5 & 72.04 \\
Extent of reduction (pct) & 73.5 & 82.0 & 72.4 & \\
Yield of SiC (pct) & 44.1 & 52.1 & 94.6 \\
\hline
\end{tabular}

*Gas composition was 1 vol pet methane, 70 vol pct hydrogen, and 29 vol pct argon. 




Fig. 10-Decomposition of methane $v s$ hydrogen content in inlet gas. Methane content in inlet gas: 1 vol pct; temperature: $1773 \mathrm{~K}$ $\left(1500{ }^{\circ} \mathrm{C}\right)$.

$$
\begin{aligned}
\mathrm{SiO}_{2}(\mathrm{~s})+\mathrm{H}_{2}(\mathrm{~g}) & =\mathrm{SiO}(\mathrm{g})+\mathrm{H}_{2} \mathrm{O}(\mathrm{g}) \\
\Delta G^{\circ} & =534.35-0.1869 T(\mathrm{~kJ}) \\
\mathrm{H}_{2} \mathrm{O}(\mathrm{g})+\mathrm{C}(\mathrm{s}) & =\mathrm{H}_{2}(\mathrm{~g})+\mathrm{CO}(\mathrm{g}) \\
\Delta G^{\circ} & =133.72-0.1419 T(\mathrm{~kJ})
\end{aligned}
$$

Increasing hydrogen content suppressed methane cracking and solid carbon deposition by Reaction [15]. Figure 10 presents the relationship between the extent of methane decomposition and the initial hydrogen content in the inlet gas at $1773 \mathrm{~K}\left(1500{ }^{\circ} \mathrm{C}\right)$. The extent of methane decomposition was calculated from the methane content in inlet gas controlled by the gas flowmeter and off gas, measured by the IR gas analyzer. Methane was almost completely decomposed when
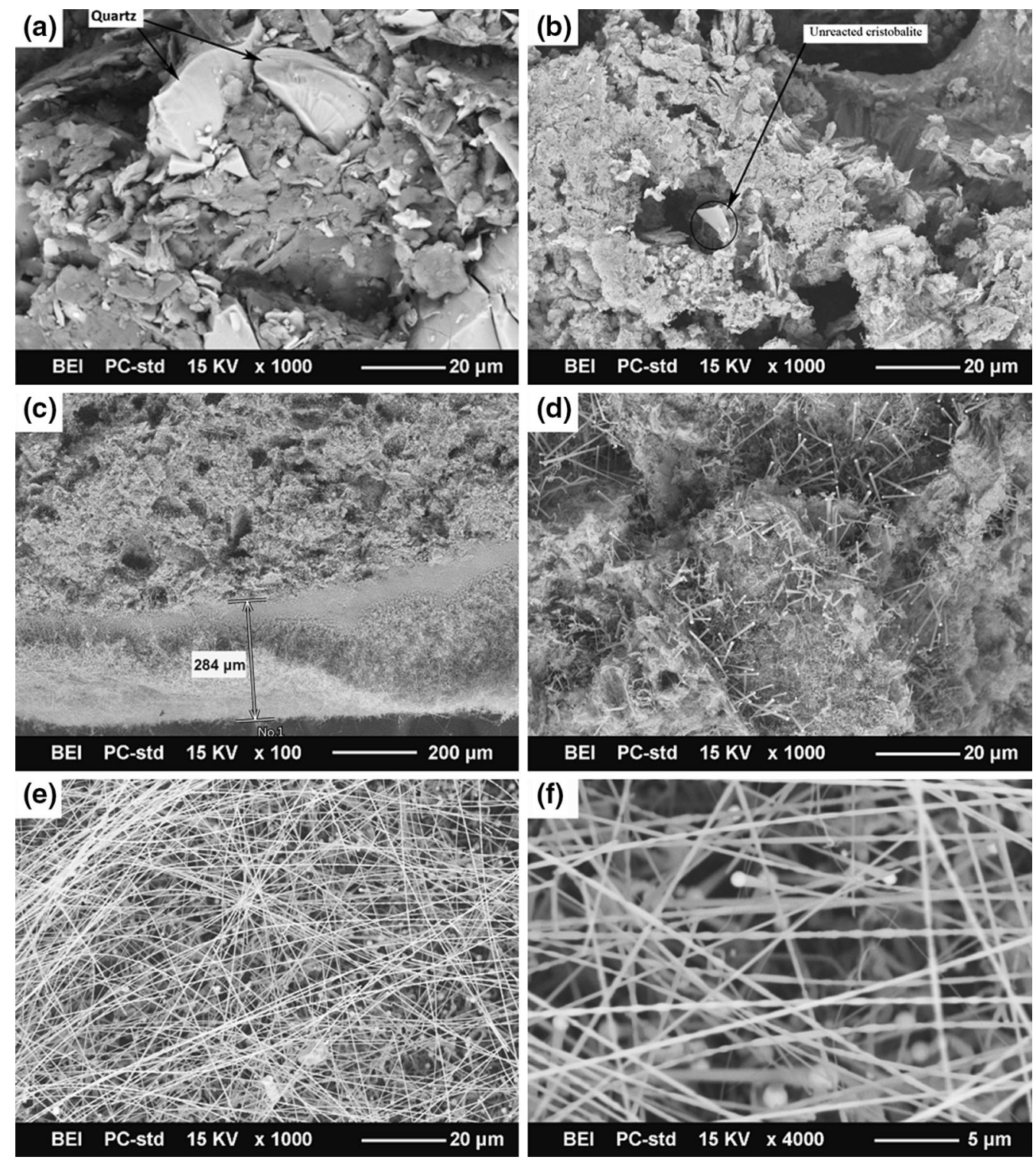

Fig. 11-SEM images of samples: $(a)$ unreduced pellet, surface section; $(b)$ after reduction at $1873 \mathrm{~K}\left(1600{ }^{\circ} \mathrm{C}\right)$ in pure argon, cross section; $(c)$ and $(d)$ after reduction at $1873 \mathrm{~K}\left(1600{ }^{\circ} \mathrm{C}\right)$ in gas mixture of 1 vol pct $\mathrm{CH}_{4}-70$ vol pet $\mathrm{H}_{2}-29$ vol pet Ar, cross section; and $(e)$ and $(f)$ after reduction at $1873 \mathrm{~K}\left(1600{ }^{\circ} \mathrm{C}\right)$ in gas mixture of 1 vol pet $\mathrm{CH}_{4}-70$ vol pet $\mathrm{H}_{2}-29$ vol pet Ar, surface section. 
hydrogen content was less than 10 vol pct. About 91 pct of methane was decomposed with $50 \mathrm{vol}$ pct of hydrogen. The suppression effect of hydrogen content on the rate of methane cracking became particularly strong when it was above 50 vol pct: only 75 pct of methane was decomposed with $70 \mathrm{vol}$ pct of hydrogen, which further decreased to $65 \mathrm{pct}$ in pure hydrogen.

Figure 11 presents the SEM images of pellets before and after reduction at $1873 \mathrm{~K}\left(1600{ }^{\circ} \mathrm{C}\right)$ in different gas atmosphere. Original pellet presented an agglomeration of mixed quartz and graphite particles (Figure 11(a)). For the reduction in pure argon (Figure 11(b)), most of the quartz was transformed to $\mathrm{SiC}$ particles, with some unreduced $\mathrm{SiO}_{2}$ observed in the form of cristobalite which was identified by XRD analysis. The morphologies of pellets reduced in the $\mathrm{CH}_{4}-\mathrm{H}_{2}-\mathrm{Ar}$ gas mixture were quite different. The image of cross section near the pellet's surface (Figure 11(c)) shows a layer of $\mathrm{SiC}$ fluff on the surface of the pellet, with a thickness from 200 to $500 \mu \mathrm{m}$. SiC whiskers with the diameter of 300 to $800 \mathrm{~nm}$ and the length of 3 to $10 \mu \mathrm{m}$ were observed in the cross-section center, as shown in Figure 11(d). These whiskers were thick and straight, grown on the iron-rich globule, suggesting that they were formed through Reaction [17] by a vapor-liquid-solid (VLS) mechanism. ${ }^{[24,28-30]}$ The iron was originated from impurities in quartz and contamination of a pellet in the process of pressing with stainless steel die. ${ }^{[24]}$ The rest $\mathrm{SiC}$ was in the form of irregular particles and flakes, similar to the structure in Figure 11(b).

SEM images obtained in further examination of the surface layer (fluff) shown in Figure 11(c) are presented in Figures 11(e) and (f). A large amount of long fibers were knit together on the surface (Figure 11(e)). These fibers grew to more than $100 \mu \mathrm{m}$ long, with a diameter of 300 to $400 \mathrm{~nm}$, quite different from the whiskers in the internal of the pellet. Furthermore, iron-rich globules were not observed at the tips of fibers, which indicates that fibers were formed by Reaction [17] via the vaporsolid (VS) mechanism. ${ }^{[19]}$ Whiskers with iron-rich globules were also observed under the fibers at the surface of pellet, as shown in Figure 11(f). Therefore, one-dimensional growth of $\mathrm{SiC}$ could take place through VLS or VS mechanism simultaneously at the surface of pellet.

\section{CONCLUSIONS}

The paper studied carbothermal reduction of quartz in the $\mathrm{CH}_{4}-\mathrm{H}_{2}-\mathrm{Ar}$ gas mixtures in the temperature range of 1573 to $1823 \mathrm{~K}\left(1300{ }^{\circ} \mathrm{C}\right.$ to $\left.1550{ }^{\circ} \mathrm{C}\right)$. The reduction of quartz mixed with graphite with $\mathrm{C} /$ $\mathrm{SiO}_{2}$ ratio of 2 in the gas mixture containing $1 \mathrm{vol}$ pet methane, 70 vol pct hydrogen, and 29 vol pct argon was close to completion in 90 minutes at $1773 \mathrm{~K}\left(1500{ }^{\circ} \mathrm{C}\right)$ and in 60 minutes at $1823 \mathrm{~K}\left(1550{ }^{\circ} \mathrm{C}\right)$.

Methane supplied a part of carbon for $\mathrm{SiC}$ synthesis and revealed high reducing capacity compared to that of solid graphite in carbothermal reduction. The reduction rate and yield of $\mathrm{SiC}$ increased with increasing methane content in the $\mathrm{CH}_{4}-\mathrm{H}_{2}-\mathrm{Ar}$ gas mixture to $2 \mathrm{vol}$ pct. Further increasing methane content caused excessive methane cracking with solid carbon deposition, which hindered access of reducing gas and decreased reduction rate. To suppress the deposition of solid carbon, the concentration of hydrogen in the gas mixture should be above $70 \mathrm{vol}$ pet (at $1773 \mathrm{~K}\left(1500{ }^{\circ} \mathrm{C}\right)$ and $1 \mathrm{vol}$ pet methane). Hydrogen was also directly involved in reduction of quartz to $\mathrm{SiO}$.

Synthesis of $\mathrm{SiC}$ in the $\mathrm{CH}_{4}-\mathrm{H}_{2}-\mathrm{Ar}$ gas mixture resulted in three different morphologies, i.e., whiskers, fibers, and irregular particles. One-dimensional growth of $\mathrm{SiC}$ in the form of whiskers and fibers was achieved by the gas-gas reaction, whereas $\mathrm{SiC}$ particles were formed through the gas-solid reactions.

\section{ACKNOWLEDGMENTS}

This research was supported under the Australian Research Council's Linkage Projects funding scheme (Project No. LP100100866) and the Norwegian Research Council under the project Kiselrox (Project No. 228722/ O30). The authors would also like to thank the Mark Wainwright Analytical Centre at the University of New South Wales for LECO analysis and the Electron Microscopy Centre (EMC) at the University of Wollongong for the electron microscopy characterization.

\section{REFERENCES}

1. S.E. Saddow: Silicon Carbide Biotechnology: A Biocompatible Semiconductor for Advanced Biomedical Devices and Applications, Elsevier Science, Amsterdam, 2011, pp. 5-10.

2. S.E. Saddow and A. Agarwal: Advances in Silicon Carbide Processing and Applications, Norwood, Artech House, 2004, pp. 2-27.

3. H.P. Martin, R. Ecke, and E. Miiller: J. Eur. Ceram. Soc., 1998, vol. 18 , pp. $1737-42$.

4. K. Järrendahl and R. Davis: Semicond. Semimet., 1998, vol. 52, pp. $1-20$

5. Y.L. Chiew and K.Y. Cheong: Mater. Sci. Eng. B, 2011, vol. 176, pp. 951-64.

6. H.N. Baumann: J. Electrochem. Soc., 1952, vol. 99, pp. 109-14.

7. G.S. Gupta, P. Vasanth Kumar, V.R. Rudolph, and M. Gupta: Metall. Mater. Trans. A, 2001, vol. 32A, pp. 1301-08.

8. Y. Yang, K. Yang, Z.M. Lin, and J.T. Li: Mater. Res. Bull., 2007, vol. 42, pp. 1625-32.

9. Y. Yang, K. Yang, Z.M. Lin, and J.T. Li: J. Eur. Ceram. Soc., 2009 , vol. 29 , pp. $175-80$.

10. O. Kordina, C. Hallin, A. Ellison, A.S. Bakin, I.G. Ivanov, A. Henry, R. Yakimova, M. Touminen, A. Vehanen, and E. Janzen: Appl. Phys. Lett., 1996, vol. 69, pp. 1456-58.

11. A. Henry, I.G. Ivanov, T. Egilsson, C. Hallin, A. Ellison, O. Kordina, U. Lindefelt, and E. Janzen: Diam. Relat. Mater., 1997, vol. 6, pp. 1289-92.

12. Q.G. Fu, H.J. Li, X.H. Shi, K.Z. Li, J. Wei, and Z.B. Hu: Mater. Chem. Phys., 2006, vol. 100, pp. 108-11.

13. O. Ostrovski and G. Zhang: AIChE J., 2006, vol. 52, pp. 300-10.

14. G. Zhang and O. Ostrovski: Metall. Mater. Trans. B, 2000, vol. 31B, pp. 129-39.

15. N. Anacleto, O. Ostrovski, and S. Ganguly: ISIJ Int., 2004, vol. 44, pp. 1480-87.

16. N. Anacleto and O. Ostrovski: Metall. Mater. Trans. B, 2004, vol. 35B, pp. 609-15.

17. J. Zhang and O. Ostrovski: Ironmak. Steelmak., 2002, vol. 29, pp. 15-21.

18. J. Zhang and O. Ostrovski: ISIJ Int., 2001, vol. 41, pp. 333-9. 
19. H.C. Lee, S. Dhage, M.S. Akhtar, D.H. Kwak, W.J. Lee, C.Y. Kim, and O.B. Yang: Curr. Appl. Phys., 2010, vol. 10, pp. S218-21. 20. S. Cetinkaya and S. Eroglu: Int. J. Refract. Met. H., 2011, vol. 29, pp. 566-72.

21. A. Agarwal and U. Pal: Metall. Mater. Trans. B, 1999, vol. 30B, pp. 295-306.

22. B.M. Moshtaghioun, A. Monshi, M.H. Abbasi, and F. Karimzadeh: Int. J. Refract. Met. H., 2011, vol. 29, pp. 645-50.

23. E. DalMartello, G. Tranell, S. Gaal, O.S. Raaness, K. Tang, and L. Arnberg: Metall. Mater. Trans. B, 2011, vol. 42B, pp. 939-50.

24. X. Li, G. Zhang, K. Tang, O. Ostrovski, and R. Tronstad: Metall. Mater. Trans. B, 2015, vol. 46B, pp. 1343-52.
25. A. Schei and S.H. Halvorsen: Proceedings from the Kjetil Motzfeldt Symposium, Trondheim, Norway. 1991. pp. 41-46.

26. A.C.D. Chaklader and A.L. Roberts: J. Am. Ceram. Soc., 1961, vol. 44 , pp. 35-41.

27. X. Wan, G. Zhang, O. Ostrovski, and H. Aral: Proceedings of the Thirteenth International Ferroalloys Congress, Karaganda, Kazakhstan. pp. 739-48.

28. G.A. Bootsma, W.F. Knippenberg, and G. Verspui: J. Cryst. Growth, 1971, vol. 11, pp. 297-309.

29. H.J. Choi and J.G. Lee: J. Mater. Sci., 1995, vol. 30, pp. 1982-86.

30. G. Urretavizcaya and J.M. Petro Lopez: J. Mater. Res., 1994, vol. 9, pp. 2981-86. 